\title{
Patent Foramen Ovale and Stroke-Current Status
}

\author{
Oh Young Bang, ${ }^{a} \mathrm{Mi} \mathrm{Ji} \mathrm{Lee,}{ }^{\mathrm{a}}$ Sookyung Ryoo, ${ }^{\mathrm{a}}$ Suk Jae Kim, ${ }^{\mathrm{a}} \mathrm{Ji}$ Won Kim ${ }^{\mathrm{b}}$ \\ ${ }^{a}$ Department of Neurology, Samsung Medical Center, Sungkyunkwan University School of Medicine, Seoul, Korea \\ bepartment of Neurology, National Medical Center, Seoul, Korea
}

Patent foramen ovale (PFO) is growing in clinical interest because of a renewed focus on embolic stroke of undetermined source (ESUS), the PFO attributable fraction (the 10-point Risk of Paradoxical Embolism score), technical advances in PFO diagnosis, and the emergence of endovascular device closure as a treatment option. However, recent randomized controlled trials of the management of patients with ESUS and PFO failed to demonstrate the superiority of closure over medical treatment. The mechanisms of stroke other than paradoxical embolism may be important in patients with ESUS and PFO. This paper reviews the current understanding of the pathophysiology of stroke and therapeutic options in patients with PFO and ESUS.

Keywords Patent foramen ovale; Stroke; Etiology; Paradoxical embolism

\author{
Correspondence: Oh Young Bang \\ Department of Neurology, Samsung \\ Medical Center, Sungkyunkwan \\ University, 81 Irwon-ro, Gangnam-gu, \\ Seoul 06351, Korea \\ Tel: +82-2-3410-3599 \\ Fax: +82-2-3410-0052 \\ E-mail: ohyoung.bang@samsung.com
}

Received: June 12, 2015

Revised: June 30, 2015

Accepted: July 8, 2015

This study was supported by the Korean Healthcare Technology R\&D Project, Ministry of Health \& Welfare (A110208).

The authors have no financial conflicts of interest.

\section{Introduction}

Cryptogenic (of unknown cause) ischemic strokes are now thought to comprise approximately $25 \%$ of all ischemic strokes. Most cryptogenic strokes are thromboembolic (embolic stroke of undetermined source [ESUS]). The thrombus is thought to originate from any of several well-established potential embolic sources, including minor-risk or covert cardiac sources (e.g., mitral annular calcification), veins via paradoxical embolism, and non-occlusive atherosclerotic plaques in the aortic arch or in the cervical or cerebral arteries. ${ }^{1}$

The foramen ovale is a hole that exists in the wall between the left and right atria of every human fetus. It normally closes during infancy. The foramen ovale does not close in approximately $25 \%$ of the general population (Figure 1). Most patients do not have any problems with patent foramen ovale (PFO), although blood is leaking from the right atrium to the left atrium (LA). Problems can arise when that blood contains a blood clot. Lechat et al. ${ }^{2}$ first called attention to PFO and stroke in
1988. They suggested that because of the high prevalence of clinically latent venous thrombosis, paradoxical embolism through PFO might be responsible for stroke more often than is usually suspected. Subsequent studies showed that PFO can be found in up to $40 \%$ of patients with ESUS. ${ }^{3,4}$

Until now, whether PFO is a risk factor for stroke has been unsettled. Results about the association of PFO with first stroke $e^{4,5}$ and with recurrent stroke ${ }^{6,7}$ have been controversial. Several factors possibly associated with increased risk of stroke recurrence in patients with PFO include a right-to-left shunt (RLS) detectable in resting conditions, ${ }^{8}$ amount of RLS under Valsalva, ${ }^{9}$ and a combination of PFO with either atrial septal aneurysm (ASA) or increased interatrial septal mobility. ${ }^{6}$ However, such findings were not confirmed in other studies. ${ }^{7,10}$ Despite these controversial results, interest in PFO has emerged recently because of a renewed focus on ESUS, especially in younger patients, technical advances in the diagnosis of PFO, and the emergence of endovascular device closure as a treatment option. ${ }^{8,11}$ 
Normal
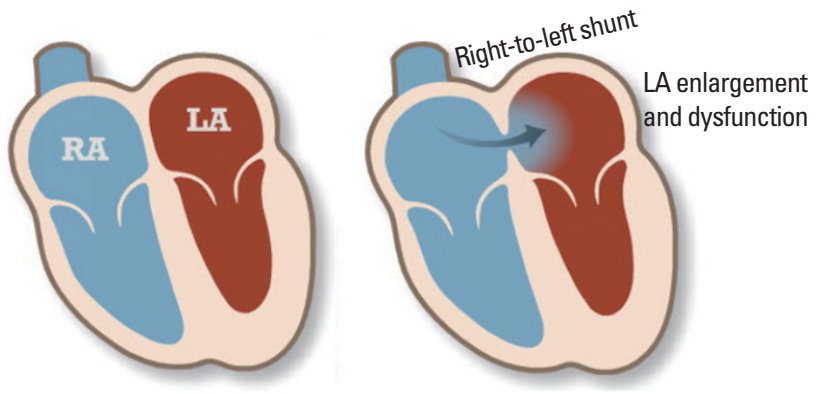

Figure 1. Schematic view of patent foramen ovale Modified from the American Heart Association. http://www.heart.org/HEARTORG/Conditions/More/ CardiovascularConditionsofChildhood/Patent-Foramen-Ovale-PFO_ UCM_469590_Article.jsp. RA, right atrium; LA, left atrium.

\section{Diagnosis of patent foramen ovale}

Various tools can be used to detect PFO and RLS (Figure 2). Transesophageal echocardiography (TEE) is considered the gold standard in the evaluation of ESUS. By TEE, the PFO size and concomitant existence of ASA, which are critical in defining high-risk PFO, as well as the possible existence of an intrapulmonary shunt ${ }^{12,13}$ may be confirmed. However, routine application of TEE is often limited in patients with acute stroke because of acute illness, mental changes, coagulopathy/bleeding tendency, and lack of patient cooperation. Echocardiography is also dependent on the properties of the equipment and on the expertise of the investigator. Agitated saline transcranial Duplex (TCD)
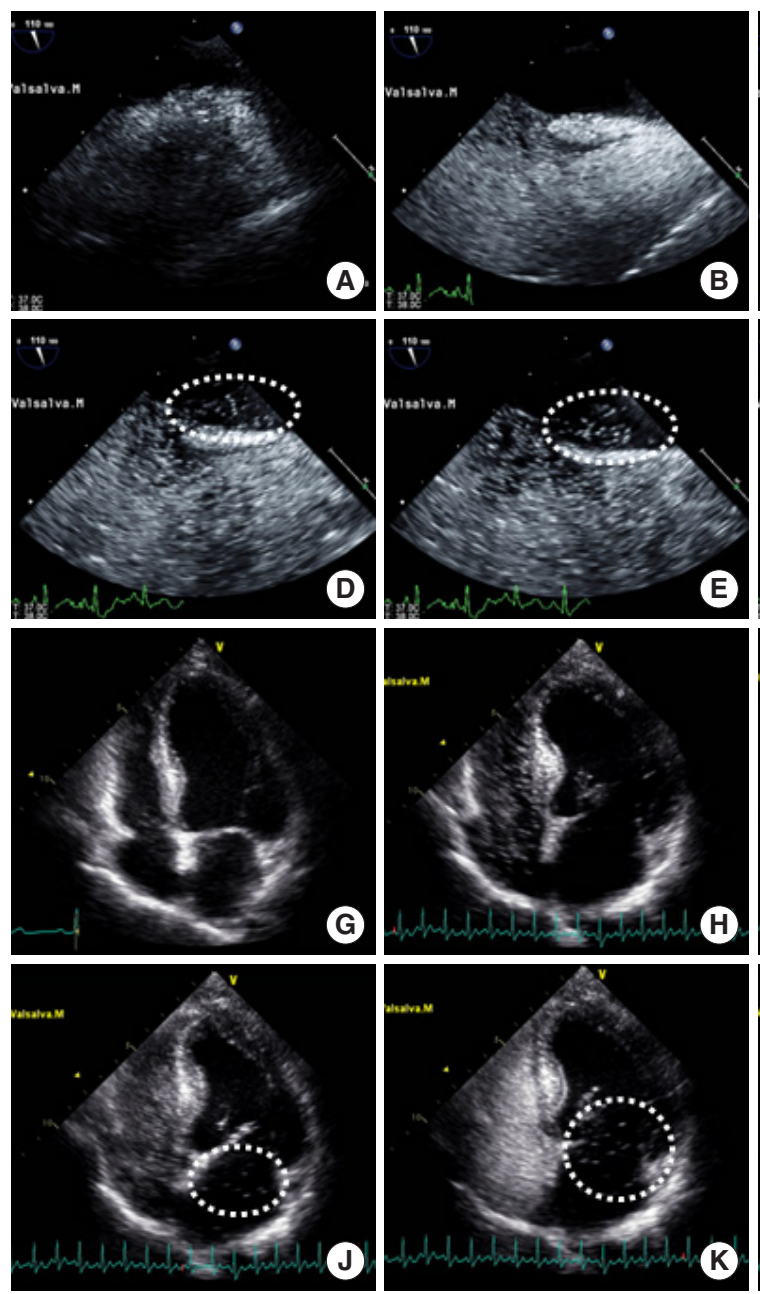
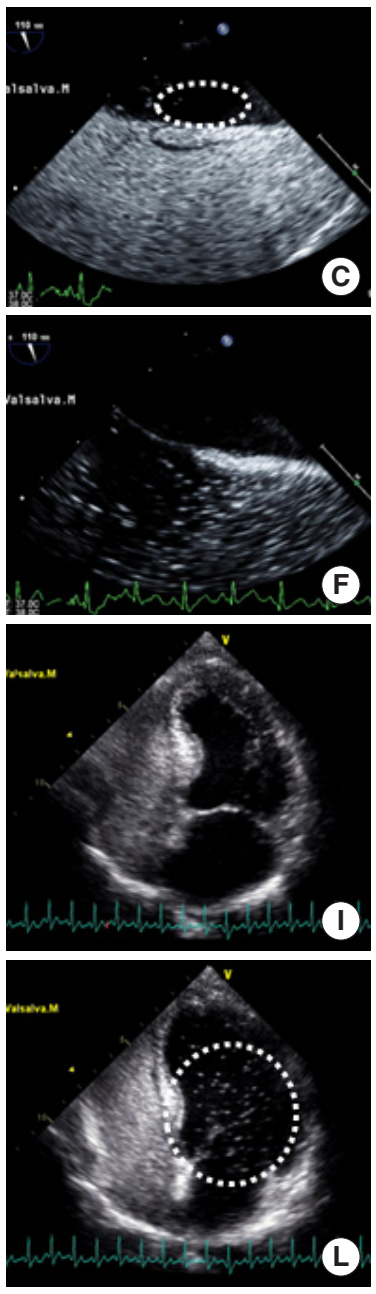

Normal TCD, 0 signals

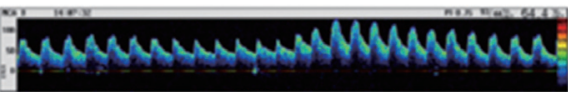

Right-to-Left Shunt, $<10$ signals

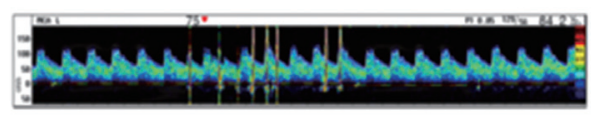

Right-to-Left Shunt, 10-25 signals

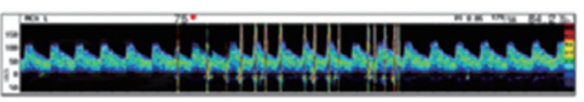

Shower pattern ( $>25$ signals)

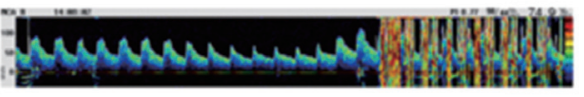

Curtain pattern

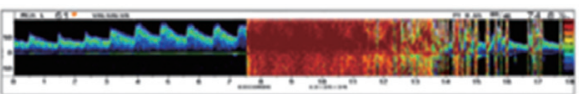

(11)

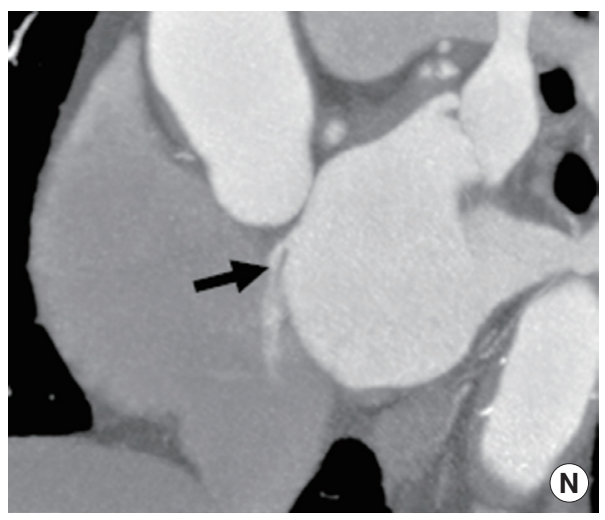

Figure 2. Diagnostic tools for patent foramen ovale and right-to-left shunt. Typical presentation of an intracardiac shunt at a $110^{\circ}$ bicaval view in a transesophageal echocardiogram. (A) Normal RA and LA in the resting state. (B) After injection of agitated saline, the RA is filled with microbubbles. (C) Immediately after the Valsalva maneuver, a few microbubbles are seen in the LA (dashed circle). (D-E) A large amount of microbubbles (>30) is filling the LA within 4-5 beats (dashed circle). (F) After 5 beats, no more shunting occurs across the interatrial septum, suggesting an intracardiac shunt. Typical presentation of an intracardiac shunt at the apical fourchamber view in a transthoracic echocardiogram. (G) Normal RA and LA. (H-I) After injection of agitated saline, the RA and RV are filled with microbubbles. (J) Immediately after the Valsalva maneuver, microbubbles are visible in the LA. (K-L) A large amount of microbubbles (>30) is filling the LA and subsequently the LV (dashed circles). The presence of delayed shunting ( $>5$ cardiac cycles) may suggest the coexistence of an extracardiac shunt. (M) Pattern of a right-to-left shunt on contrast transcranial Doppler ultrasonography. Modified from the CODICIA study. www.estudio-codicia.org. (N) Multidetector computed tomography showed a contrast agent jet from the LA to the RA toward the inferior vena cava. 
monitoring is based on the intracranial detection of intravenously injected microemboli. The Valsalva maneuver is much easier when the agitated saline TCD technique is performed. Therefore, the size and functional relevance of RLS can more easily be assessed using TCD than TEE. ${ }^{14}$ The TCD technique has a similar sensitivity and specificity as TEE. ${ }^{14,15}$ The agitated saline TCD technique is reportedly safe in patients with ESUS being evaluated for RLS detection. ${ }^{16}$ RLS can also be detected noninvasively using dye dilution or ear oximetry methods with high sensitivity and specificity when compared with TEE ${ }^{17}$ Recently, cardiac computed tomographic angiography was used to confirm the presence of a PFO with high accuracy. ${ }^{18}$

\section{The probability of having PF0 as a cause or coincidence of stroke}

In patients with ESUS, one-third of discovered PFO are likely to be incidental and, hence, not benefit from closure, while PFO could be pathogenic in certain situations. ${ }^{19}$ The probability that a PFO discovered in the setting of an ESUS is stroke-related vs. incidental depends on the patient's age, presence of traditional risk factors, and type of cerebral infarct. ${ }^{20}$ Therefore, there have been efforts to identify the patient characteristics that may be important in patient selection in therapeutic decision-making. Kent and colleagues recently reported that younger patients without vascular risk factors are much more likely to have PFO than patients without risk factors. ${ }^{21}$ Using the clinical and brain imaging features, they suggested the 10-point Risk of Paradoxical Embolism (RoPE) score. ${ }^{22}$ If a patient with ESUS shows a high RoPE score, it is likely that ESUS is attributable to PFO (Figure 3). Beside the clinical and brain imaging features, laboratory findings may be useful for predicting outcomes and determining a treatment strategy. One recent study showed that the coexistence of PFO and a high D-dimer level increased the risk of recurrent ischemic stroke in patients with PFO-related stroke. $^{23}$

Patients with ESUS show distinct clinicoradiological features depending on the underlying causes: aortic arch atheroma, PFO, and paroxysmal atrial fibrillation. ${ }^{24}$ Other authors and we have shown that patients with PFO had healthy vascular risk factor profiles and displayed posterior circulation involvement compared to patients with aortic arch atheroma or paroxysmal atrial fibrillation. ${ }^{25}$ One brain single-photon emission computed tomography study showed that during the Valsalva maneuver the rate of blood flow in the posterior circulation was higher than that in the anterior circulation, which could be a possible explanation for the posterior predominance of paradoxical embolism. ${ }^{26}$ We have reported that stroke phenotypes differed among patients with stroke and PFO and that the amount of RLS determined the lesion patterns on diffusion-weighted imaging (DWI); most patients with massive RLS showed small infarcts upon DWI, whereas large infarcts were observed in more than $40 \%$ of patients with mild amounts of RLS. ${ }^{27}$ These results suggest that mechanisms of stroke other than the paradoxical mechanism may play an important role in patients with large embolic stroke (Figure 4). However, controversial results exist in the association of DWI lesion characteristics and the PFO size, ${ }^{28-30}$ and the presence of deep vein thrombosis ${ }^{31}$ and interatrial septal abnormalities (ASA ${ }^{28}$ and septal excursion distance ${ }^{29}$ ) were also associated with a large brain infarct.

Although the risk of stroke recurrence is low in patients with PFO-related stroke (Figure 3), the biological relevance of PFO is unknown. PFO could be the cause of silent brain infarcts (Figure 5). Silent infarcts are associated with subtle deficits and increase the risk of subsequent stroke and dementia by approximately two-fold. ${ }^{32}$ Compared to small vessel disease, silent brain

\begin{tabular}{lc}
\hline Characteristics & Points \\
\hline No history of hypertension & 1 \\
No history of diabetes & 1 \\
No history of stroke or TIA & 1 \\
Nonsmoker & 1 \\
Cortical infarct on imaging & 1 \\
Age (year) & \\
18-29 & 5 \\
$30-39$ & 4 \\
$40-49$ & 3 \\
$50-59$ & 2 \\
$60-69$ & 1 \\
$\geq 70$ & 0 \\
Maximum score & 10
\end{tabular}

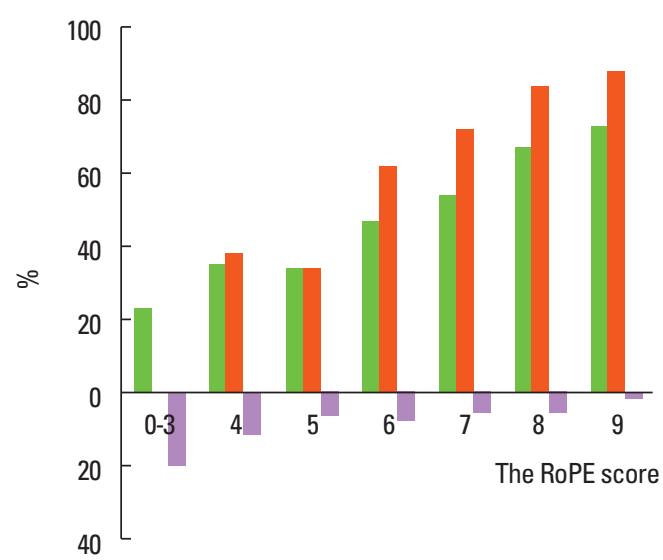

Prevalence of patients with a PFO

PFO-attributable fraction

Estimated 2-year stroke/TIA recurrence rate in cryptogenic stroke with PFO

Figure 3. The Risk of Paradoxical Embolism (RoPE) score and the risk of stroke recurrence. Modified from Calvet and Mas. ${ }^{20}$ 

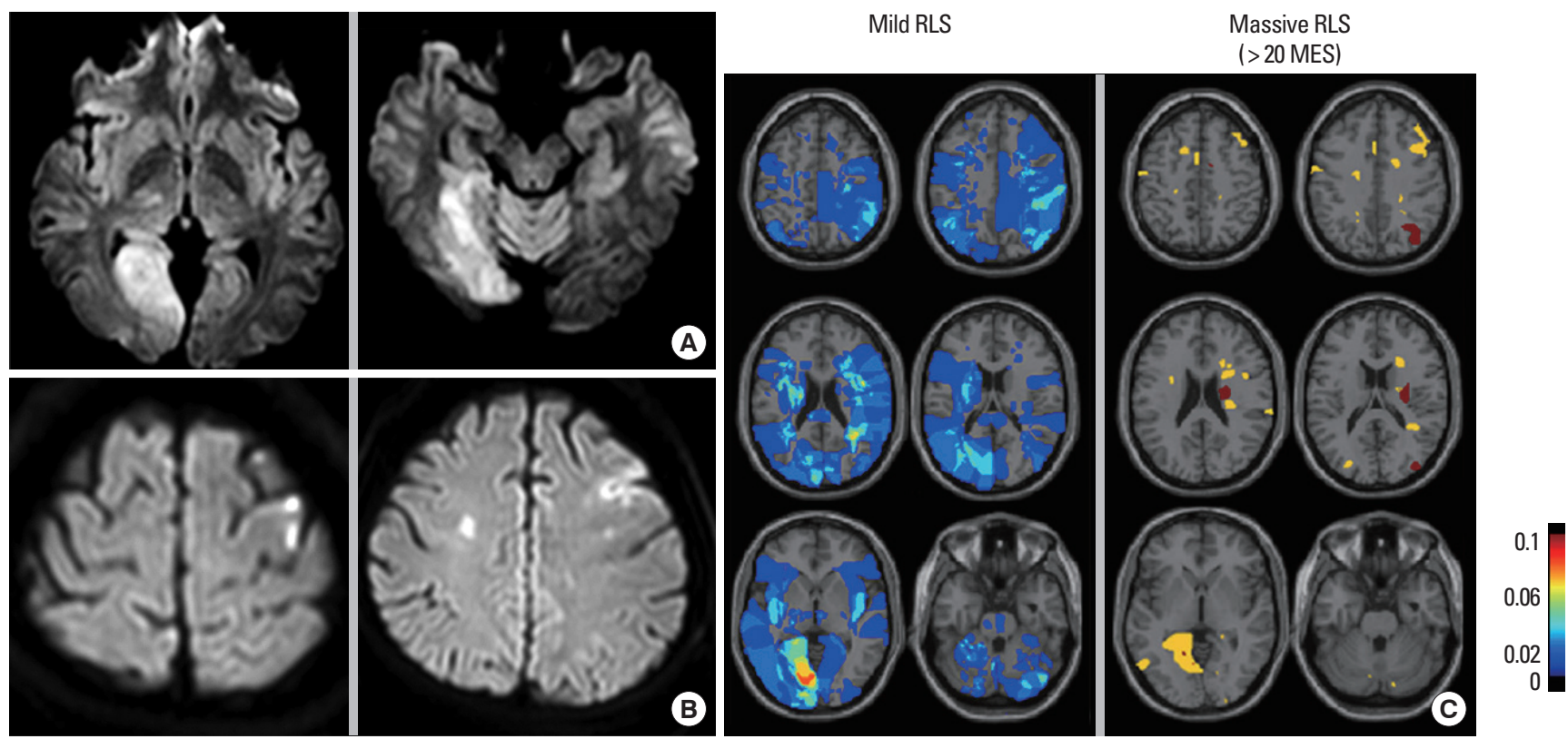

Figure 4. Typical acute infarction patterns of (A) posterior circulation involvement and (B) multiple small cortical infarcts on diffusion-weighted imaging. (C) Contour images of the mean values of affected areas in patients with acute infarcts and PFO. Modified from Kim et al. ${ }^{16}$

infarcts associated with cardiac disease are underrecognized. Both PFO and PFO closure are reportedly associated with silent brain infarcts. ${ }^{33}$ The influence of cerebral emboli caused by PFO on white matter lesions and cognitive impairment has been reported. ${ }^{3436}$ In the ICONS (Identification of the Cause of Silent Cerebral Infarction in Healthy Subjects) study, which prospectively evaluated the presence of paradoxical embolism in healthy subjects with silent brain infarcts, RLS was observed in $51 \% .{ }^{37}$ Therefore, PFO should be considered in young patients with superficially located silent infarcts and relatively healthy risk profiles.

\section{Prevention of stroke in patients with PF0- related stroke}

Paradoxical embolism has been considered a main mechanism of stroke in patients with PFO. ${ }^{38}$ Paradoxical embolism was considered a possible diagnosis if there was an arterial embolism without demonstrable sources; coexistence of deep venous thrombosis, pulmonary embolism, or cough/other Valsalva maneuver immediately preceding the onset of stroke symptoms; and an RLS. ${ }^{6}$ However, in the prospective Spanish multicenter Right-to-Left Shunt in Cryptogenic Stroke (CODICIA) study, there was no association between massive RLS and recurrent stroke. ${ }^{7}$ Clinical conditions, such as prothrombotic conditions (deep vein thrombosis, prolonged immobility/postoperative period, and the Valsalva maneuver), are often considered as clinical indicators of paradoxical embolism. However, in data from the Tufts PFO registry, these features were not associated with embolism recurrence. ${ }^{39}$ Moreover, deep vein thrombosis is infrequently detected in patients with ESUS and PFO.

In addition, controversy remains regarding the benefit of percutaneous closure of PFO among patients with ESUS. Three randomized controlled trials of the management of patients with ESUS and PFO have been reported recently (Table 1): the Evaluation of the STARFlex Septal Closure System in Patients With a Stroke and/or Transient Ischemic Attack Due to Presumed Paradoxical Embolism Through a Patent Foramen Ovale (CLOSURE I) ${ }^{40}$ the Randomized Evaluation of Recurrent Stroke Comparing PFO Closure to Established Current Standard of Care Treatment (RESPECT), ${ }^{41}$ and the Clinical Trial Comparing Percutaneous Closure of Patent Foramen Ovale Using the Amplatzer PFO Occluder with Medical Treatment in Patients with Cryptogenic Embolism (PC Trial). ${ }^{42}$ All three randomized clinical trials failed to demonstrate superiority of closure compared with medical treatment. ${ }^{40-42}$ In the CLOSURE I trial, PFO closure increased the risk of new-onset atrial fibrillation..$^{40}$ These failures may be caused by inappropriate patient selection (many patients had transient ischemic attacks rather than superficial infarcts), wrong devices (procedural failure $>10 \%$ ), or wrong study design (unblinded and selection bias $)^{43,44}$ but also could be caused by a limitation in the efficacy of PFO closure in patients with ESUS and PFO. Low annual risk of recurrent stroke in patients with PFO-related stroke might be considered for the determination of therapeutic options. The complication rates were different depending on the 

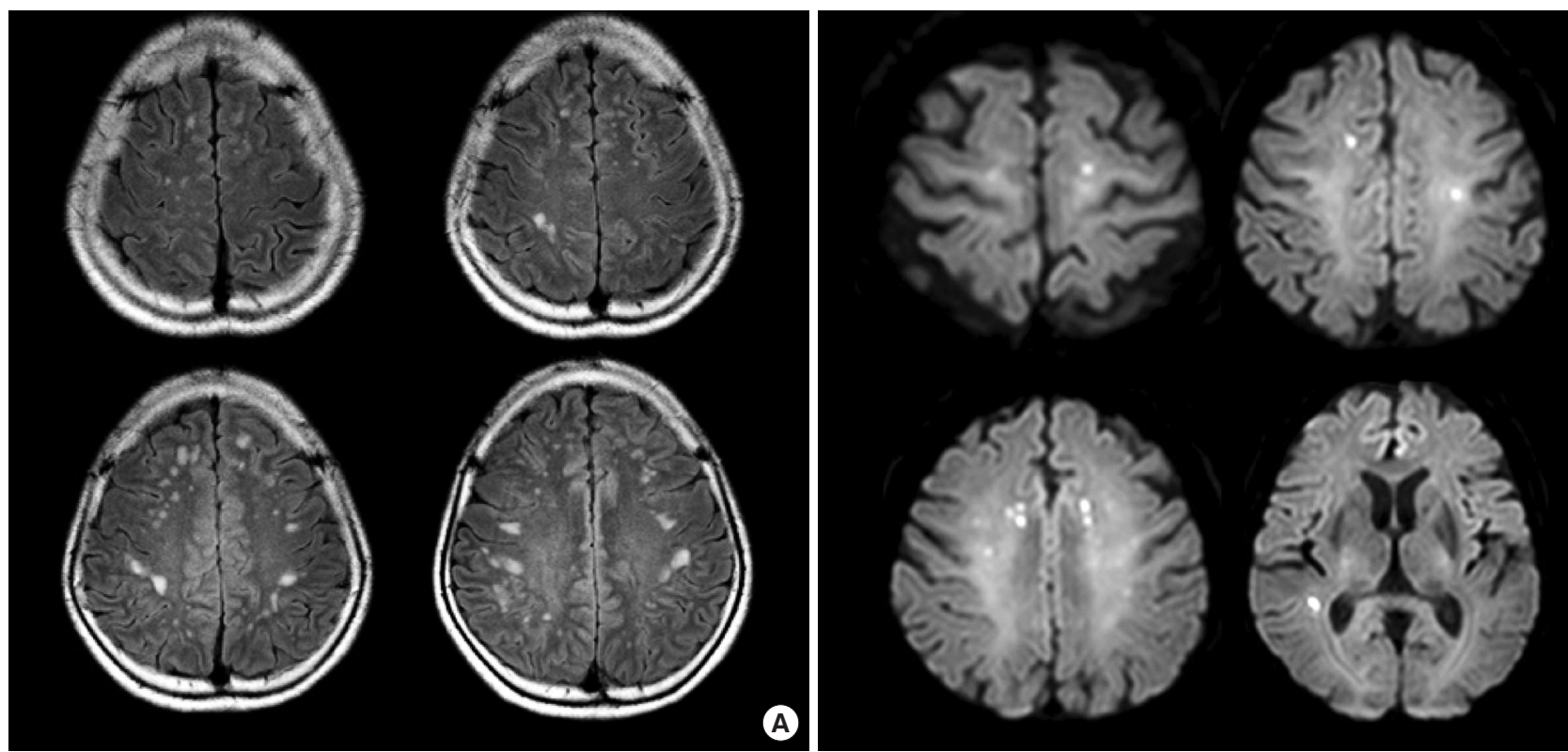

B

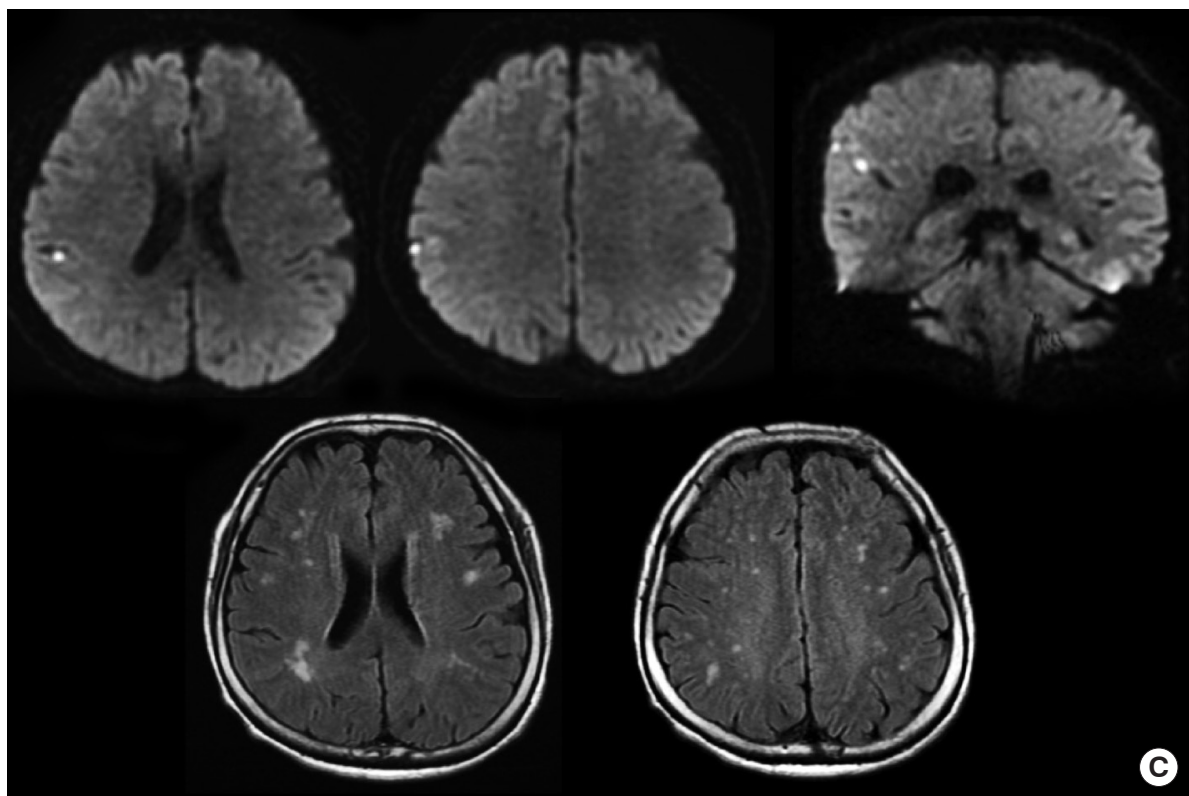

C)
Figure 5. Silent small cortical infarcts in patients with PFO. (A) A 50-year-old apparently healthy man underwent brain MRI for a medical checkup. The MRI showed multiple small ischemic changes on bilateral centrum semiovale on a fluid-attenuated inversion recovery (FLAIR) image. A trascranial Doppler agitated saline test revealed a right-to-left shunt. (B) A 75-year-old woman underwent MRI for the purpose of preoperative evaluation for stroke risk. Incidental findings included multiple small acute infarcts involving multivascular territories on diffusionweighted imaging (DWI). Transesophageal echocardiogram revealed a normal aorta but an intracardiac shunt. (C) A 62-year-old apparently health woman with a history of migraine headaches underwent brain MRI for her chronic headaches. MRI showed multiple silent but acute small cortical infarcts on DWI (upper image) and silent small cortical infarcts on FLAIR (lower image).

Table 1. Results of clinical trials of PFO closure

\begin{tabular}{|c|c|c|c|}
\hline & CLOSURE I $(2012)^{40}(n=909)$ & RESPECT $(2013)^{41}(n=980)$ & $P C(2013)^{42}(n=414)$ \\
\hline Inclusion & Stroke or TIA & Stroke or TIA, peripheral TE & Stroke or TIA, peripheral TE \\
\hline \multicolumn{4}{|l|}{ Groups } \\
\hline 1. Closure device & STARFlex & Amplatzer & Amplatzer \\
\hline 2. Medical arm & Aspirin, warfarin & Aspirin, clopidogrel, aggrenox, warfarin & Aspirin, ticlopidine, clopidogrel, warfarin \\
\hline \multirow{2}{*}{ Outcome } & 2 years & 8 years & 4 years \\
\hline & Death, stroke or TIA & Death, stroke or TIA, peripheral TE & Death, stroke or TIA, peripheral TE \\
\hline $\begin{array}{l}\text { Primary end point, } \mathrm{HR}(95 \% \mathrm{Cl}) \\
\text { (medical vs. closure arm) }\end{array}$ & $\begin{array}{l}0.78(0.45-1.35) \\
\text { (M 5.5\% vs. C } 6.8 \%)\end{array}$ & $\begin{array}{l}0.63(0.24-1.62) \\
\text { (M } 5.2 \% \text { vs. C } 3.4 \%)\end{array}$ & $\begin{array}{l}0.63(0.24-1.62) \\
\text { (M } 3.4 \% \text { vs. C } 5.2 \%)\end{array}$ \\
\hline $\begin{array}{l}\text { Stroke or TIA, HR (95\% CI) } \\
\text { (medical vs. closure arm) }\end{array}$ & $\begin{array}{l}0.82(0.38-1.76) \\
\text { (M 2.4\% vs. C } 0.6 \%)\end{array}$ & $\begin{array}{l}0.49(0.22-1.11) \\
(\mathrm{M} 3.3 \% \text { vs. C } 1.9 \%)\end{array}$ & $\begin{array}{l}0.45(0.16-1.29) \\
(\mathrm{M} 5.2 \% \text { vs. C } 3.4 \%)\end{array}$ \\
\hline $\begin{array}{c}\text { New-onset AF, OR (95\% CI) } \\
\text { (medical vs. closure arm) }\end{array}$ & $\begin{array}{l}9.11(2.71-30.58)^{*} \\
(\mathrm{M} 0.7 \% \text { vs. C } 5.8 \%)\end{array}$ & $\begin{array}{l}1.93(0.17-21.37) \\
\text { (M 1.5\% vs. C } 3.1 \%)\end{array}$ & $\begin{array}{l}3.15 \text { (0.63-15.80) } \\
\text { (M 1.0\% vs. C } 3.0 \%)\end{array}$ \\
\hline
\end{tabular}

${ }^{*} P<0.05$

TIA, transient ischemic attack; TE, thromboembolism; $M$, medical arm; C, closure arm; $\mathrm{HR}$, hazard ratio; $\mathrm{OR}$, odds ratio; $\mathrm{Cl}$, confidence interval; $\mathrm{AF}$, atrial fibrillation. 
device types (STARFlex vs. Amplatzer) used in the clinical trials. Development of a newer device with a higher procedural success rate and fewer proarrhythmic effects is needed.

In a prospective study of $\mathrm{PFO}$ closure, although patients with large RLS received percutaneous closure, older age, multiple previous strokes, and ASA but not PFO closure were associated with stroke or mortality. ${ }^{45}$ Therefore, although most studies have focused on PFO closure, the mechanisms of stroke other than paradoxical embolism may be important in patients with ESUS and PFO (Figure 6). First, migraine is commonly found in patients with $\mathrm{PFO}$ and is a risk factor for some etiopathogenic subtypes of cerebral infarcts such as dissections and PFO. A recent Duplex study showed that migraineurs have isolated cerebral endothelial dysfunction restricted to the posterior circulation in the absence of systemic endothelial dysfunction. ${ }^{46} \mathrm{Sec}-$ ond, occult atrial fibrillation (AF) may exist in patients with ESUS and incidental PFO. LA dysfunction could be a marker of incident AF, atrial thrombi, and thromboembolic risks of $\mathrm{AF}^{47,48}$ The LA functions of PFO patients were reportedly lower than normal, similar to patients with $\mathrm{AF}^{49}$ In addition, increased incidence of interatrial block due to stretching of the interatrial septum was reported in patients with ESUS and PFO, suggesting that atrial arrhythmia might underlie and mediate

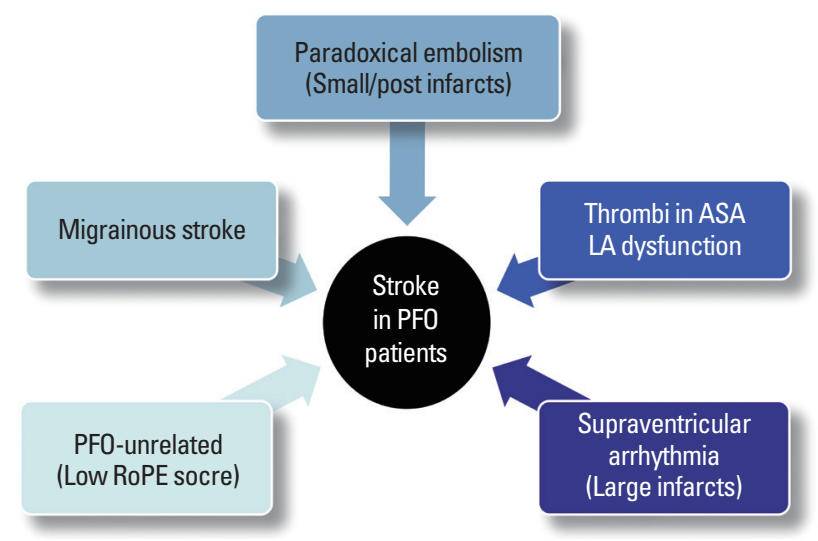

Figure 6. Possible mechanisms of stroke in patients with PFO. thrombus formation. ${ }^{50}$ Because atrial dysfunction and concomitant $\mathrm{AF}$ have been suggested as a mechanism of stroke related to $\mathrm{PFO},{ }^{49,50}$ longer electrocardiogram monitoring should be considered for patients with larger infarcts or echocardiographic findings of LA dysfunction.

Finally, thrombus within the ASA or LA may contribute to arterial embolism. Cardiac thrombus formation secondary to localized hypercoagulable conditions related to structural changes in the LA, left atrial appendage, and ASA have been suggested as potential mechanisms for stroke. Using intraprocedural intracardiac echocardiographic assessment in candidates for PFO closure, Rigatelli and colleagues demonstrated that ASA were associated with LA dysfunction, and spontaneous echocontrast was observed in $52 \%$ of ASA. ${ }^{49}$ This may be true for patients without ASA. Recently, reports about the association between LA abnormality and cryptogenic stroke have been increasing. ${ }^{51}$ LA enlargement related to PFO and RLS might precipitate incident and recurrent embolism from $\mathrm{PFO}$ in the absence of overt LA dysfunction.

The American Heart Association/American Stroke Association recently recommended treatment guidelines in patients with PFO and ESUS (Table 2). ${ }^{52}$ Data to establish whether anticoagulation is superior to aspirin for secondary stroke prevention in patients with PFO are insufficient. Randomized controlled trials comparing non-vitamin $\mathrm{K}$ antagonists versus antiplatelet agents in patients with ESUS are ongoing (Dabigatran Etexilate for Secondary Stroke Prevention in Patients With Embolic Stroke of Undetermined Source [RE-SPECT ESUS], NCT02239120, and Rivaroxaban Versus Aspirin in Secondary Prevention of Stroke and Prevention of Systemic Embolism in Patients With Recent Embolic Stroke of Undetermined Source [NAVIGATE ESUS], NCT02313909).

\section{Conclusion}

PFO is an important risk factor for ESUS. PFO could be a cause or coincidence of stroke. In addition, PFO closure could

Table 2. Guideline for second prevention of stroke in patients with patent foramen ovale

\begin{tabular}{|c|c|}
\hline $\begin{array}{l}\text { There are insufficient data to establish whether anticoagulation is equivalent or superior to aspirin } \\
\text { for secondary stroke prevention in patients with PFO }\end{array}$ & (Class Ilb; Level of Evidence B) \\
\hline $\begin{array}{l}\text { For patients with an ischemic stroke or TIA and a PFO who are not undergoing anticoagulation therapy, } \\
\text { antiplatelet therapy is recommended }\end{array}$ & (Class l; Level of Evidence B) (Revised recommendation) \\
\hline $\begin{array}{l}\text { For patients with an ischemic stroke or TIA and both a PFO and a venous source of embolism, } \\
\text { anticoagulation is indicated, depending on stroke characteristics }\end{array}$ & (Class l; Level of Evidence A) \\
\hline When anticoagulation is contraindicated, an inferior vena cava filter is reasonable & (Class Ila; Level of Evidence Q) (New recommendation) \\
\hline $\begin{array}{l}\text { For patients with a cryptogenic ischemic stroke or TIA and a PFO without evidence for deep vein } \\
\text { thrombosis, available data do not support a benefit for PFO closure }\end{array}$ & (Class III; Level of Evidence A) (Revised recommendation) \\
\hline $\begin{array}{l}\text { In the setting of PFO and deep vein thrombosis, PFO closure by a transcatheter device might be } \\
\text { considered, depending on the risk of recurrent deep vein thrombosis }\end{array}$ & (Class Ilb; Level of Evidence C) (New recommendation) \\
\hline
\end{tabular}


be helpful but also could be harmful (arrhythmogenic). The PFO attributable fraction as well as stroke mechanisms (paradoxical embolism vs. others) may differ greatly among patients. Further advances in our understanding of stroke mechanisms are needed together with advances in closure devices. In the meantime, therapeutic approaches tailored to the patient's characteristics are needed.

\section{References}

1. Hart RG, Diener HC, Coutts SB, Easton JD, Granger CB, O’Donnell MJ, et al. Embolic strokes of undetermined source: the case for a new clinical construct. Lancet Neurol 2014;13: 429-438.

2. Lechat P, Mas JL, Lascault G, Loron P, Theard M, Klimczac M, et al. Prevalence of patent foramen ovale in patients with stroke. N Engl J Med 1988;318:1148-1152.

3. Hagen PT, Scholz DG, Edwards WD. Incidence and size of patent foramen ovale during the first 10 decades of life: an autopsy study of 965 normal hearts. Mayo Clin Proc 1984;59:17-20.

4. Overell JR, Bone I, Lees KR. Interatrial septal abnormalities and stroke: a meta-analysis of case-control studies. Neurology 2000;55:1172-1179.

5. Kraywinkel K, Jauss M, Diener HC, Weimar C. Patent foramen ovale, atrial septum aneurysm, and stroke. An examination of the status of recent evidence. Nervenarzt 2005;76:935942.

6. Mas JL, Arquizan C, Lamy C, Zuber M, Cabanes L, Derumeaux $\mathrm{G}$, et al. Recurrent cerebrovascular events associated with patent foramen ovale, atrial septal aneurysm, or both. $N$ Engl J Med 2001;345:1740-1746.

7. Serena J, Marti-Fàbregas J, Santamarina E, Rodríguez JJ, PerezAyuso MJ, Masjuan J, et al. Recurrent stroke and massive rightto-left shunt: results from the prospective Spanish multicenter (CODICIA) study. Stroke 2008;39:3131-3136.

8. De Castro S, Cartoni D, Fiorelli M, Rasura M, Anzini A, Zanette EM, et al. Morphological and functional characteristics of patent foramen ovale and their embolic implications. Stroke 2000;31:2407-2413.

9. Anzola GP, Zavarize P, Morandi E, Rozzini L, Parrinello G. Transcranial Doppler and risk of recurrence in patients with stroke and patent foramen ovale. Eur J Neurol 2003;10:129-135.

10. Homma S, Sacco RL, Di Tullio MR, Sciacca RR, Mohr JP. Effect of medical treatment in stroke patients with patent foramen ovale: patent foramen ovale in Cryptogenic Stroke Study. Circulation 2002;105:2625-2631.

11. Furlan AJ. Brief history of patent foramen ovale and stroke. Stroke 2015;46:e35-37.
12. Abushora MY, Bhatia N, Alnabki Z, Shenoy M, Alshaher M, Stoddard MF. Intrapulmonary shunt is a potentially unrecognized cause of ischemic stroke and transient ischemic attack. $J$ Am Soc Echocardiogr 2013;26:683-690.

13. Bhatia N, Abushora MY, Donneyong MM, Stoddard MF. Determination of the optimum number of cardiac cycles to differentiate intra-pulmonary shunt and patent foramen ovale by saline contrast two- and three-dimensional echocardiography. Echocardiography 2014;31:293-301.

14. Jauss M, Zanette E. Detection of right-to-left shunt with ultrasound contrast agent and transcranial Doppler sonography. Cerebrovasc Dis 2000;10:490-496.

15. Droste DW, Reisener M, Kemény V, Dittrich R, Schulte-Altedorneburg G, Stypmann J, et al. Contrast transcranial Doppler ultrasound in the detection of right-to-left shunts. Reproducibility, comparison of 2 agents, and distribution of microemboli. Stroke 1999;30:1014-1018.

16. Tsivgoulis G, Stamboulis E, Sharma VK, Heliopoulos I, Voumvourakis K, Teoh HL, et al. Safety of transcranial Doppler 'bubble study' for identification of right to left shunts: an international multicentre study. J Neurol Neurosurg Psychiatry 2011; 82:1206-1208.

17. Karttunen V, Ventilä M, Ikäheimo M, Niemelä M, Hillbom M. Ear oximetry: a noninvasive method for detection of patent foramen ovale: a study comparing dye dilution method and oximetry with contrast transesophageal echocardiography. Stroke 2001;32:448-453.

18. Kim YJ, Hur J, Shim CY, Lee HJ, Ha JW, Choe KO, et al. Patent foramen ovale: diagnosis with multidetector CT--comparison with transesophageal echocardiography. Radiology 2009; 250:61-67.

19. Alsheikh-Ali AA, Thaler DE, Kent DM. Patent foramen ovale in cryptogenic stroke: incidental or pathogenic? Stroke 2009; 40:2349-2355.

20. Calvet D, Mas JL. Closure of patent foramen ovale in cryptogenic stroke: a never ending story. Curr Opin Neurol 2014;27: 13-19.

21. Kent DM, Thaler DE. Is patent foramen ovale a modifiable risk factor for stroke recurrence? Stroke 2010;41:S26-30.

22. Kent DM, Ruthazer R, Weimar C, Mas JL, Serena J, Homma S, et al. An index to identify stroke-related vs incidental patent foramen ovale in cryptogenic stroke. Neurology 2013;81:619-625.

23. Kim YD, Song D, Nam HS, Lee K, Yoo J, Hong GR, et al. D-dimer for prediction of long-term outcome in cryptogenic stroke patients with patent foramen ovale. Thromb Haemost 2015;114.

24. Bang OY, Ovbiagele B, Kim JS. Evaluation of cryptogenic stroke with advanced diagnostic techniques. Stroke 2014;45:11861194. 
25. Kim BJ, Sohn H, Sun BJ, Song JK, Kang DW, Kim JS, et al. Imaging characteristics of ischemic strokes related to patent foramen ovale. Stroke 2013;44:3350-3356.

26. Hayashida K, Fukuchi K, Inubushi M, Fukushima K, Imakita $S$, Kimura K. Embolic distribution through patent foramen ovale demonstrated by (99m)Tc-MAA brain SPECT after Valsalva radionuclide venography. J Nucl Med 2001;42:859-863.

27. Kim JW, Kim SJ, Yoon CW, Park CH, Kang KW, Kim SK, et al. Association between the amount of right-to-left shunt and infarct patterns in patients with cryptogenic embolic stroke: a transcranial Doppler study. Int J Stroke 2013;8:657-662.

28. Bonati LH, Kessel-Schaefer A, Linka AZ, Buser P, Wetzel SG, Radue EW, et al. Diffusion-weighted imaging in stroke attributable to patent foramen ovale: significance of concomitant atrial septum aneurysm. Stroke 2006;37:2030-2034.

29. Akhondi A, Gevorgyan R, Tseng CH, Slavin L, Dao C, Liebeskind DS, et al. The association of patent foramen ovale morphology and stroke size in patients with paradoxical embolism. Circ Cardiovasc Interv 2010;3:506-510.

30. Jung JM, Lee JY, Kim HJ, Do Y, Kwon SU, Kim JS, et al. Patent foramen ovale and infarct volume in cryptogenic stroke. J Stroke Cerebrovasc Dis 2013;22:1399-1404.

31. Yasaka M, Otsubo R, Oe H, Minematsu K. Is stroke a paradoxical embolism in patients with patent foramen ovale? Intern Med 2005;44:434-438.

32. Vermeer SE, Longstreth WT Jr, Koudstaal PJ. Silent brain infarcts: a systematic review. Lancet Neurol 2007;6:611-619.

33. Hassell ME, Nijveldt R, Roos YB, Majoie CB, Hamon M, Piek JJ, et al. Silent cerebral infarcts associated with cardiac disease and procedures. Nat Rev Cardiol 2013;10:696-706.

34. Purandare N, Oude Voshaar RC, McCollum C, Jackson A, Burns A. Paradoxical embolisation and cerebral white matter lesions in dementia. Br J Radiol 2008;81:30-34.

35. Liu JR, Plötz BM, Rohr A, Stingele R, Jansen O, Alfke K. Association of right-to-left shunt with frontal white matter lesions in T2-weighted MR imaging of stroke patients. Neuroradiology 2009;51:299-304.

36. Di Tullio MR, Jin Z, Russo C, Elkind MS, Rundek T, Yoshita $\mathrm{M}$, et al. Patent foramen ovale, subclinical cerebrovascular disease, and ischemic stroke in a population-based cohort. J Am Coll Cardiol 2013;62:35-41.

37. Kim SJ, Shin HY, Ha YS, Kim JW, Kang KW, Na DL, et al. Paradoxical embolism as a cause of silent brain infarctions in healthy subjects: the ICONS study (Identification of the Cause of Silent Cerebral Infarction in Healthy Subjects). Eur J Neurol 2013; 20:353-360.

38. Steiner MM, Di Tullio MR, Rundek T, Gan R, Chen X, Liguori $\mathrm{C}$, et al. Patent foramen ovale size and embolic brain imaging findings among patients with ischemic stroke. Stroke 1998;29: 944-948

39. Kitsios GD, Lasker A, Singh J, Thaler DE. Recurrent stroke on imaging and presumed paradoxical embolism: a cross-sectional analysis. Neurology 2012;78:993-997.

40. Furlan AJ, Reisman M, Massaro J, Mauri L, Adams H, Albers GW, et al. Closure or medical therapy for cryptogenic stroke with patent foramen ovale. N Engl J Med 2012;366:991-999.

41. Carroll JD, Saver JL, Thaler DE, Smalling RW, Berry S, MacDonald LA, et al. Closure of patent foramen ovale versus medical therapy after cryptogenic stroke. N Engl J Med 2013;368: 1092-1100.

42. Meier B, Kalesan B, Mattle HP, Khattab AA, Hildick-Smith D, Dudek D, et al. Percutaneous closure of patent foramen ovale in cryptogenic embolism. N Engl J Med 2013;368:1083-1091.

43. Spencer FA, Lopes LC, Kennedy SA, Guyatt G. Systematic review of percutaneous closure versus medical therapy in patients with cryptogenic stroke and patent foramen ovale. BMJ Open 2014;4:e004282.

44. Thaler DE, Wahl A. Critique of closure or medical therapy for cryptogenic stroke with patent foramen ovale: the hole truth? Stroke 2012;43:3147-3149.

45. Alushi B, Biasco L, Orzan F, Omedé P, Sciuto F, Moretti C, et al. Patent foramen ovale treatment strategy: an Italian large prospective study. J Cardiovasc Med (Hagerstown) 2014;15:761768.

46. Rajan R, Khurana D, Lal V. Interictal cerebral and systemic endothelial dysfunction in patients with migraine: a case-control study. J Neurol Neurosurg Psychiatry 2014.

47. Agmon Y, Khandheria BK, Gentile F, Seward JB. Echocardiographic assessment of the left atrial appendage. J Am Coll Cardiol 1999;34:1867-1877.

48. Leung DY, Boyd A, Ng AA, Chi C, Thomas L. Echocardiographic evaluation of left atrial size and function: current understanding, pathophysiologic correlates, and prognostic implications. Am Heart J 2008; 156:1056-1064.

49. Rigatelli G, Aggio S, Cardaioli P, Braggion G, Giordan M, Dell'avvocata F, et al. Left atrial dysfunction in patients with patent foramen ovale and atrial septal aneurysm: an alternative concurrent mechanism for arterial embolism? JACC Cardiovasc Interv 2009;2:655-662.

50. Cotter PE, Martin PJ, Pugh PJ, Warburton EA, Cheriyan J, Belham M. Increased incidence of interatrial block in younger adults with cryptogenic stroke and patent foramen ovale. Cerebrovasc Dis Extra 2011;1:36-43.

51. Yaghi S, Moon YP, Mora-McLaughlin C, Willey JZ, Cheung K, Di Tullio MR, et al. Left atrial enlargement and stroke recurrence: the northern Manhattan stroke study. Stroke 2015;46: 
1488-1493.

52. Kernan WN, Ovbiagele B, Black HR, Bravata DM, Chimowitz MI, Ezekowitz MD, et al. Guidelines for the prevention of stroke in patients with stroke and transient ischemic attack: a guideline for healthcare professionals from the American Heart Association/American Stroke Association. Stroke 2014;45: 2160-2236. 